Article

\title{
Effect of the Concentration of Pigment Slurry on the Film Performances of Waterborne Wood Coatings
}

\author{
Xiaoxing Yan ${ }^{1,2, *}$, Yijuan Chang ${ }^{2}$ and Xingyu Qian ${ }^{2}$ \\ 1 Co-Innovation Center of Efficient Processing and Utilization of Forest Resources, \\ Nanjing Forestry University, Nanjing 210037, China \\ 2 College of Furnishings and Industrial Design, Nanjing Forestry University, Nanjing 210037, China; \\ changyijuan@njfu.edu.cn (Y.C.); qianxingyu@njfu.edu.cn (X.Q.) \\ * Correspondence: yanxiaoxing@nuaa.edu.cn; Tel.: +86-25-8542-7528
}

Received: 28 July 2019; Accepted: 29 September 2019; Published: 2 October 2019

\begin{abstract}
Wood surface decoration and protection has become a topic of public concern. In this paper, a temperature-sensitive and reversible thermochromic waterborne wood coating was prepared by using Chinese fir board as the base material and a waterborne wood coating with the pigment slurry of thermochromic microcapsules as the paint base. The optical properties, mechanical properties and chemical resistance of the waterborne wood coating were tested, and its microstructure was analyzed. The results showed that when the concentration of thermochromic pigment slurry was $30.0 \%$, the thermochromic property of the waterborne wood coating was best. The gloss of the waterborne wood coating with $15.0 \%$ pigment slurry of thermochromic microcapsules was high. The concentration of thermochromic pigment slurry had no effect on the adhesion, impact resistance, or chemical resistance of the waterborne wood coating. Based on the above results, the waterborne wood coating on Chinese fir had the best comprehensive performance when the concentration of thermochromic pigment slurry was $15.0 \%$. This work will provide a technical reference for the industrialization of the thermochromic coating film on wood.
\end{abstract}

Keywords: thermochromic pigment slurry; microcapsule; waterborne wood coating; film performance

\section{Introduction}

A thermochromic system refers to a color change of printed patterns and text when the material is heated to a certain temperature [1]. When the temperature drops to the original temperature, the solution of thermochromic microcapsules returns to the original color [2]. Temperature-sensitive reversible systems of thermochromic microcapsules can be divided into organic reversible [3], inorganic reversible, [4] and liquid crystal reversible categories [5]. Solvents in a thermochromic system determine the thermochromic temperature of temperature-sensitive materials [6,7]. The thermosensitive discoloration temperature is generally changed by changing the solvent used [8].

Vukoje et al. [9] studied the biodegradability of ultraviolet thermochromic ink on three different paper materials (synthetic, recovered, and bulk). The results showed that the thicker the ink binder layer on the surface of microcapsules, the slower the degradation rate of microcapsules. Kavcic et al. [10] applied different printing materials on the printed display and deposited thermochromic ink on the first and second layers. The effects of printing materials, the thickness of the thermochromic ink layer, varnish, temperature and light resistance on the operability of the display were studied. The results showed that the choice of printing materials played an important role in the operability of the display. Panak et al. [11] used digital cameras to record bulk systems, dry pigments, water and ink solvent formulations, and dry coatings on different paper substrates. The results showed that the dry layer of the water-based thermochromic ink coated on paper has a high value in the total length and contrast 
of the optical path. Kim et al. [12] studied thermochromic inkjet ink pens and applied them to plain paper and stored them for a month without distortion. Zhu et al. [13,14] prepared microcapsules with good stability and a smaller particle size by using urea-formaldehyde as the shell material and a thermochromic compound as the core material. The effects of thermochromic compounds and impregnation conditions on the properties and thermal stability of thermochromic wood veneers were investigated. The results showed that the thermochromic wood veneers had the best performance when impregnated in a thermochromic compound suspension for 2 min at $65^{\circ} \mathrm{C}$. A common preparation of thermochromically-active material follows the general rule: leuco-dye (electron donor) + color developer (electron acceptor) + co-solvent are used to form a composite, which is the phase-changing material. With a change of temperature, the color change is changed by the electron movement between the electron donor and the electron acceptor. These chromotropic materials are mainly used in paper, wood and printing materials, and little work deals with the study of thermochromic materials used in waterborne wood coatings.

Adding thermochromic ink to waterborne wood coatings can change the color of waterborne coatings with the change of temperature, make the product display different colors with the change of season, and make the product more humanized and changeable. The waterborne wood coating is environmentally friendly because it does not increase VOC emissions [15,16], and it is superior to oil-based paint in environmental sustainability and performance stability $[17,18]$. Microencapsulation is needed to keep the entire thermochromic system together and protect it from the surrounding environment. Bisphenol A as a color developer is one of the most widely used industrial compounds in the world. It has a low toxicity and is widely used in packaging of canned food and beverages, milk bottles, water bottles, and sealants for tooth fillings. Bisphenol A is considered to have some possible health effects and many products try to be bisphenol A free. Microencapsulation can reduce the toxic release and volatility of a discolored system, and improve the stability of a thermochromic system. Specifically, in this experiment, the release of bisphenol A was very little and encapsulated in microcapsules, which meets the requirements of environmental safety. In this paper, Chinese fir (Cunninghamia lanceolata), which is a widely used wooden material [19], was used as the substrate to study the effects of a pigment slurry of thermochromic microcapsules on the color difference, gloss, mechanics, and chemical resistance of a waterborne coating in order to establish a foundation for the application of chromotropic coatings in wood products.

\section{Experimental Materials and Methods}

\subsection{Experimental Materials}

The main components of methyl red (as leuco agent, $M_{\mathrm{w}}: 269.30 \mathrm{~g} / \mathrm{mol}$, CAS No.: 493-52-7), bisphenol A (as color developer, $M_{\mathrm{w}}: 228.29 \mathrm{~g} / \mathrm{mol}$, CAS No.: 80-05-7), melamine ( $M_{\mathrm{w}}: 126.12 \mathrm{~g} / \mathrm{mol}$, CAS No.: 108-78-1), and heterogeneous decanol (as dispersing agent, $M_{\mathrm{w}}: 158.00 \mathrm{~g} / \mathrm{mol}$, CAS No.: 68526-85-2) were supplied by Huancai Discoloration Technology Co., Ltd., Shenzhen, China. Sodium dodecylbenzene sulfonate $\left(M_{\mathrm{w}}: 348.48 \mathrm{~g} / \mathrm{mol}\right.$, CAS No.: $\left.25155-30-0\right), 37.0 \%$ formaldehyde solution $\left(M_{\mathrm{w}}: 30.03 \mathrm{~g} / \mathrm{mol}\right.$, CAS No.: 50-00-0), anhydrous ethanol ( $M_{\mathrm{w}}: 46.07 \mathrm{~g} / \mathrm{mol}$, CAS No.: 64-17-5), lauryl alcohol (co-solvent, $M_{\mathrm{w}}: 186.34 \mathrm{~g} / \mathrm{mol}$, CAS No.: 112-53-8), citric acid monohydrate $\left(M_{\mathrm{w}}: 210.14 \mathrm{~g} / \mathrm{mol}\right.$, CAS No.: 5949-29-1) and triethanolamine ( $M_{\mathrm{w}}: 149.19 \mathrm{~g} / \mathrm{mol}$, CAS No.: 102-71-6) were supplied by Xilong Chemical Co., Ltd., Guangzhou, China. A waterborne wood coating was supplied by Yihua Lifestyle Technology Co., Ltd., Shantou, China. The waterborne wood coating consisted of a waterborne acrylic copolymer dispersion (concentration 90.0\%), matting agent (concentration $2.0 \%$ ), additives (concentration 2.0\%) and water (concentration 6.0\%). Chinese fir boards (100 $\mathrm{mm} \times 100 \mathrm{~mm} \times$ $12 \mathrm{~mm}$, uniform material color, 300 pieces, after ordinary mechanical sanding) were supplied by Yihua Lifestyle Technology Co., Ltd., Shantou, China. The studied wood samples have a radial sawn wood texture. The $15.0 \% \mathrm{NaCl}$ solution and $70.0 \%$ medical ethanol were supplied by Otopp Biotechnology 
Co., Ltd., Hangzhou, China. Detergent was supplied by Hutchison WhiteCat Co., Ltd., Shanghai, China. Red ink was supplied by Fine Stationery Co., Ltd., Shanghai, China.

\subsection{Preparation of the Pigment Slurry}

The thermochromic microcapsules were prepared by in situ polymerization. The $5.0 \mathrm{~g}$ melamine, $10.0 \mathrm{~g} 37.0 \%$ formaldehyde solution and $10.0 \mathrm{~mL}$ deionized water were poured into a $250 \mathrm{~mL}$ beaker. The $\mathrm{pH}$ value was adjusted by triethanolamine to 8.5-9.0. Then the solution was kept in a constant temperature water bath at $70{ }^{\circ} \mathrm{C}$ with stirring at $700 \mathrm{rpm}$ to obtain a transparent solution as the wall material solution. One gram of sodium dodecylbenzene sulfonate was dissolved completely in $99.00 \mathrm{~g}$ deionized water, and 1.0\% sodium dodecylbenzene sulfonate aqueous solution was obtained. Then $1.0 \mathrm{~g}$ methyl red, $1.0 \mathrm{~g}$ bisphenol A and $10.0 \mathrm{~g}$ lauryl alcohol were added to the aqueous sodium dodecylbenzene sulfonate solution, and the beaker was placed in a $60^{\circ} \mathrm{C}$ water bath and stirred for $30 \mathrm{~min}$ at $1200 \mathrm{rpm}$ to obtain a stable core material emulsion. Then the wall material solution was added to the core material emulsion and stirred until evenly mixed. The citric acid monohydrate was added to adjust the solution $\mathrm{pH}$ to $4.0-5.0$. The system was reacted at $60^{\circ} \mathrm{C}$ for $3 \mathrm{~h}$, then cooled down to room temperature. After several rinses with deionized water and absolute ethanol, the product was put into the oven and dried at $25^{\circ} \mathrm{C}$ for $24 \mathrm{~h}$, and $6.3 \mathrm{~g}$ of thermochromic microcapsules were obtained. The thermochromic microcapsules were added to $10.0 \mathrm{~mL}$ heterogeneous decanol, and they were mixed evenly to obtain the pigment slurry.

\subsection{Preparation of Coatings}

First, the Chinese fir boards were placed at room temperature and 50.0\% $\pm 5.0 \%$ relative humidity for one week to achieve a balanced moisture concentration of the substrate. Then $5.0 \mathrm{~g}$ pigment slurry was added to $95.0 \mathrm{~g}$ waterborne wood coating, mixed evenly, and the waterborne thermochromic coating with the mass fraction of $5.0 \%$ pigment slurry was prepared. Other proportions are also produced according to this method. Then the pigment slurry of thermochromic microcapsules with the concentrations of $10.0 \%, 15.0 \%, 20.0 \%, 25.0 \%$, and $30.0 \%$, respectively, was added to the waterborne wood coatings and mixed evenly. The composition is shown in Table 1. Then the Chinese fir boards were coated using an SZQ tetrahedral fabricator (Tianjin Jinghai Science and Technology Testing Machinery Factory, Tianjin, China). The coating was dried in air at room temperature for $30 \mathrm{~min}$ and then sanded using 800 grit sandpaper, and a dry cloth was used to wipe off the dust. Sandpaper with 800 grit has little effect on microcapsules. The above process was repeated three times. The sample was transferred to a $35^{\circ} \mathrm{C}$ electric blast drying oven, heated until the mass no longer changed, and then naturally cooled to room temperature. The thickness of the dry waterborne wood coating was about $40 \mu \mathrm{m}$.

Table 1. Components of waterborne wood coating.

\begin{tabular}{cccc}
\hline $\begin{array}{c}\text { Concentration of } \\
\text { Pigment Slurry (\%) }\end{array}$ & $\begin{array}{c}\text { Weight of Pigment } \\
\text { Slurry (g) }\end{array}$ & $\begin{array}{c}\text { Weight of Waterborne } \\
\text { Coating (g) }\end{array}$ & $\begin{array}{c}\text { Weight of Thermochromic } \\
\text { Coating }(\mathbf{g})\end{array}$ \\
\hline 0 & 0 & 100.0 & 100.0 \\
5.0 & 5.0 & 95.0 & 100.0 \\
10.0 & 10.0 & 90.0 & 100.0 \\
15.0 & 15.0 & 85.0 & 100.0 \\
20.0 & 20.0 & 80.0 & 100.0 \\
25.0 & 25.0 & 75.0 & 100.0 \\
30.0 & 30.0 & 70.0 & 100.0 \\
\hline
\end{tabular}

\subsection{Testing and Characterization}

The microstructure of the waterborne wood coatings was analyzed using a Quanta 200 environment scanning electron microscope (SEM), FEI Company (Hillsboro, OR, USA). A HP-2136 colorimeter 
(Zhuhai Tianchuang Instrument Co., Ltd., Zhuhai, China) was used to directly measure the CIELAB coordinates (D65 and $10^{\circ}$ observer) values of the waterborne wood coatings. The waterborne wood coated with different concentrations of pigment slurry was heated on an HHP1 heating plate (Shanghai Hengyue Medical Devices Co., Ltd., Shanghai, China). While the coating was slowly heated, the surface temperature of the coating was measured by a temperature sensor, and at the same time the chromatic values of the coating were measured by a colorimeter to determine the temperature dependence of the results. The waterborne wood coating with different concentrations of pigment slurry of thermochromic microcapsules was heated from 18 to $40^{\circ} \mathrm{C}$, and the change in color was recorded. Where $L^{*}$ is the lightness, the larger value indicates that the surface of the object to be measured is light, and a smaller value indicates that the color of the object to be measured is dark. The $a^{*}$ indicates the change of color from red to green, the value is positive which means the color is red, and the negative value means green. The $b^{*}$ indicates the change of color from yellow to blue. A positive $b^{*}$ value indicates that the surface of the object to be measured is yellow, and the $b^{*}$ value is negative to indicate blue. The $C^{*}$ indicates color chroma, and $h^{*}$ indicates the hue. Then, the color difference was calculated by the following formula (1) [20]:

$$
\Delta E^{*}=\left[\left(\Delta L^{*}\right)^{2}+\left(\Delta a^{*}\right)^{2}+\left(\Delta b^{*}\right)^{2}\right]^{1 / 2}
$$

where: $\Delta L^{*}$ (brightness difference) $=L_{1}{ }^{*}-L_{2}{ }^{*}, \Delta a^{*}$ (red and green difference) $=a_{1}{ }^{*}-a_{2}{ }^{*}$, and $\Delta b^{*}$ (yellow blue difference) $=b_{1}{ }^{*}-b_{2}{ }^{*} . L_{1}{ }^{*}, a_{1}{ }^{*}$ and $b_{1}{ }^{*}$ are all initial values $\left(18^{\circ} \mathrm{C}\right)$, while $L_{2}{ }^{*}, a_{2}{ }^{*}$, and $b_{2}{ }^{*}$ are the values after the temperature change. An HG268 gloss meter, produced by $3 \mathrm{NH}$ Technology Co., Ltd., Shenzhen, China was used to measure the gloss of the waterborne wood coating. The incident angle of light used in this study was $60^{\circ}$. The measurement site of the gloss values was parallel to the wood grain. According to the standard of GB/T1732-93 [21], the impact strength (Tianjin Jingkelian Material Testing Machine Co., Ltd., Tianjin, China) was measured by a QCJ impactor. In the impact test, a $1.0 \mathrm{~kg}$ ball falls $50 \mathrm{~cm}$ onto the surface of the coating, and the deformation of the coating was observed. According to GB/T 1720-89 [22], a QFZ-II coating adhesion tester (Tianjin JingKelian Material Testing Machine Co., Ltd.) was used to determine the adhesion of the coating. According to GB/T 1733-93 [23], the chemical resistance of the coating was determined using $15.0 \%$ sodium chloride solution, $70.0 \%$ medical ethanol, detergent, and red ink. First, filter paper was immersed in the sodium chloride solution, medical ethanol, detergent, and red ink respectively, and then placed on the surface of the coating. The coating was covered with a glass cover and allowed to stand for $24 \mathrm{~h}$. The ageing and stability test was measured in the ZN ultraviolet weather resistance tester (Nanjing Environmental Test Equipment Co., Ltd., Nanjing, China). A mixture of rosin and paraffin was coated on the side and the back of Chinese fir boards, leaving a $10.0 \times 5.0 \mathrm{~cm}^{2}$ waterborne wood coating, and the samples were put in the $\mathrm{ZN}$ ultraviolet weather resistance tester for $200 \mathrm{~h}$. All experiments were repeated four times with an error of less than $5.0 \%$.

\section{Results and Discussion}

\subsection{Effect of Pigment Slurry Concentration of Thermochromic Microcapsules on Optical Properties}

Effects of the pigment slurry concentration of microcapsules on color value from 18 to $40^{\circ} \mathrm{C}$ of waterborne wood coating were tested. The variation trend of the color difference of waterborne wood coating is shown in Figure 1. As can be seen from Figure 1, the waterborne wood coating without the pigment slurry had a color difference from 18 to $40^{\circ} \mathrm{C}$ of $0.7-1.0$ and had no color change effect. The waterborne wood coating with the pigment slurry concentrations of $5.0 \%-30.0 \%$ at $18-28{ }^{\circ} \mathrm{C}$ had color differences of $0.7-6.8$, and the color did not change significantly. When the waterborne wood coating with the pigment slurry concentration of $15.0 \%$ was heated to $30^{\circ} \mathrm{C}$, the color changed significantly, and the color difference value was 13.5, which is the maximum color difference. The color of the waterborne wood coating with the pigment slurry concentration of $15.0 \%$ changed from red to pale red color with the increase of temperature. The color difference for the pigment slurry concentration of $15.0 \%$ was also relatively large near $32{ }^{\circ} \mathrm{C}$, and the color difference changed significantly. The color 
difference of the waterborne wood coating with the pigment slurry concentration of $30.0 \%$ at $30{ }^{\circ} \mathrm{C}$ and $32{ }^{\circ} \mathrm{C}$ was 4.3 and 27.6 , respectively. The same color difference of the waterborne wood coating was obtained by returning to the initial temperature as shown in Figure 2, which showed good discoloration ability. When the maximum temperature in the room was near $30{ }^{\circ} \mathrm{C}$, people generally feel hot [24], so the thermochromic waterborne wood coating should have better discoloration coloration near $30^{\circ} \mathrm{C}$. That was to say, the waterborne wood coating with a pigment slurry concentration of $15.0 \%$ and $30.0 \%$ had a good color change effect. In case of $30.0 \%$ concentration, the change is much sharper.

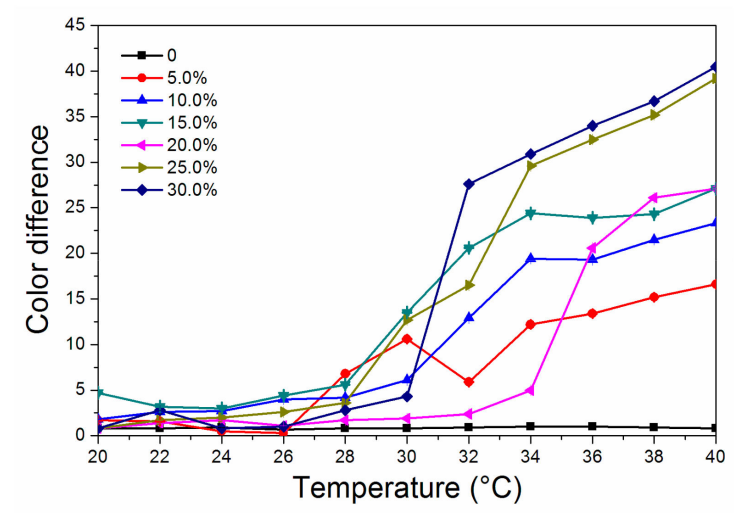

Figure 1. Effect of pigment slurry concentration on the color difference of waterborne wood coatings from 18 to $40^{\circ} \mathrm{C}$.

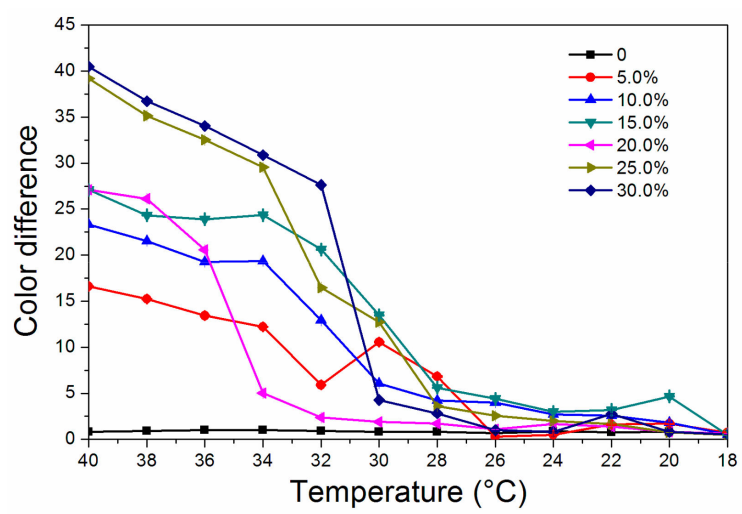

Figure 2. Effect of pigment slurry concentration on the color difference of waterborne wood coatings from 40 to $18^{\circ} \mathrm{C}$.

The thermochromic waterborne wood coating was lit at $60^{\circ}$, and the effects of different concentrations of pigment slurry on the gloss change of the waterborne wood coating were observed. As shown in Table 2, the gloss of the waterborne wood coating decreased with the increase of thermochromic pigment slurry concentration. The main reason was that with the increase of the concentration of thermochromic pigment slurry, the number of particles in the thermochromic pigment slurry in the waterborne wood coating increased, resulting in a decrease in the reflection of light. Considering the high cost of pigment slurry, the addition of more pigment slurry had a negative impact on other properties of the coating, such as gloss, so the waterborne wood coating with a pigment slurry concentration of $15.0 \%$ was better. 
Table 2. Effect of pigment slurry concentration on the gloss of waterborne wood coating.

\begin{tabular}{cc}
\hline Concentration of Thermochromic Pigment Slurry (\%) & $\mathbf{6 0}^{\circ}$ Gloss $(\mathbf{\%})$ \\
\hline 0 & $45.5 \pm 0.8$ \\
5.0 & $40.9 \pm 0.3$ \\
10.0 & $38.4 \pm 0.5$ \\
15.0 & $37.2 \pm 0.3$ \\
20.0 & $35.7 \pm 1.0$ \\
25.0 & $33.2 \pm 0.5$ \\
30.0 & $26.1 \pm 0.6$ \\
\hline
\end{tabular}

\subsection{Effect of Pigment Slurry Concentration of Thermochromic Microcapsules on Mechanical Properties}

The adhesion level was judged by the damaged area of the waterborne wood coating, and the smaller the area, the better the adhesion of the waterborne wood coating. The adhesion level of the waterborne wood coating with discolored pigment slurry concentration of $0-30.0 \%$ was 0 , and the adhesion was good. Therefore, the concentration of the pigment slurry of thermochromic microcapsules had no effect on the adhesion of the waterborne wood coating. As can be seen from Table 3, the waterborne wood coating without the thermochromic pigment slurry had an impact resistance of $5.0 \mathrm{~kg} \cdot \mathrm{cm}$. The waterborne wood coating with a thermochromic pigment slurry concentration of $5.0 \%-20.0 \%$ had an impact resistance of $4.0 \mathrm{~kg} \cdot \mathrm{cm}$. When the concentration was more than $20.0 \%$, the impact resistance of the waterborne wood coating gradually increased with the increase in the thermochromic microcapsule concentration of the pigment slurry, but the difference was not large, which may be due to the low impact strength of Chinese fir itself.

Table 3. Effect of pigment slurry concentration on the impact resistance of coating.

\begin{tabular}{cc}
\hline Concentration of Thermochromic Pigment Slurry (\%) & Impact Resistance (kg.cm) \\
\hline 0 & $5.0 \pm 0.1$ \\
5.0 & $4.0 \pm 0.1$ \\
10.0 & $4.0 \pm 0.1$ \\
15.0 & $4.0 \pm 0.1$ \\
20.0 & $4.0 \pm 0.1$ \\
25.0 & $5.0 \pm 0.1$ \\
30.0 & $6.0 \pm 0.1$ \\
\hline
\end{tabular}

\subsection{Effect of Pigment Slurry Concentration of Thermochromic Microcapsules on Chemical Resistance}

At room temperature, the chemical resistance test of $0-30.0 \%$ pigment slurry concentrations of thermochromic microcapsules in a waterborne wood coating on a Chinese fir surface was carried out with $15.0 \% \mathrm{NaCl}$ solution, $70.0 \%$ medical ethanol, detergent, and red ink. The $L^{*}, a^{*}, b^{*}, C^{*}$, and $h^{*}$ values of the waterborne wood coating were measured before and $24 \mathrm{~h}$ after the experiment. The color difference of the waterborne wood coating after chemical resistance was calculated according to formula (1) (shown in Table 4). The chemical resistance test showed that there was no blushing, blister, or dissolution of the film. The relationship between the degree of discoloration and the color difference is shown in Table 5 [25]. The lower the chemical resistance rating of the waterborne wood coating, the better the performance of the waterborne wood coating. As can be seen from Table 6, the chemical resistance level of the waterborne wood coating with thermochromic pigment slurry concentrations of $0-30.0 \%$ on the ethanol and detergent was 0 and without discoloration. The waterborne wood coating with a thermochromic pigment slurry concentration of $0-30.0 \%$ was level 0 or 1 for the red ink and $\mathrm{NaCl}$, which had very slight discoloration. The concentration of the thermochromic pigment slurry had little effect on the chemical resistance level. It is possible that the pigment slurry itself has better chemical resistance, so the original chemical resistance of the coating was maintained after adding it. 
Table 4. Effect of pigment slurry concentration on the color difference of waterborne wood coating for chemical resistance.

\begin{tabular}{ccccc}
\hline $\begin{array}{c}\text { Concentration of Thermochromic } \\
\text { Pigment Slurry (\%) }\end{array}$ & $\mathrm{NaCl}$ & Detergent & Ethanol & Red Ink \\
\hline 0 & $0.8 \pm 0$ & $0.8 \pm 0$ & $1.0 \pm 0$ & $1.9 \pm 0$ \\
5.0 & $1.1 \pm 0$ & $1.1 \pm 0$ & $1.0 \pm 0$ & $1.9 \pm 0$ \\
10.0 & $1.8 \pm 0$ & $0.5 \pm 0$ & $0.7 \pm 0$ & $1.3 \pm 0$ \\
15.0 & $1.0 \pm 0$ & $0.7 \pm 0$ & $1.2 \pm 0$ & $1.2 \pm 0$ \\
20.0 & $0.9 \pm 0$ & $1.0 \pm 0$ & $1.0 \pm 0$ & $1.3 \pm 0$ \\
25.0 & $1.2 \pm 0$ & $1.3 \pm 0$ & $1.0 \pm 0$ & $1.2 \pm 0$ \\
30.0 & $0.7 \pm 0$ & $1.5 \pm 0$ & $1.3 \pm 0$ & $1.2 \pm 0$ \\
\hline
\end{tabular}

Table 5. Range of color difference corresponding to the level of discoloration.

\begin{tabular}{ccc}
\hline Level & Degree of Discoloration & Color Difference \\
\hline 0 & no discoloration & $\leq 1.5$ \\
1 & very slight discoloration & $1.6-3.0$ \\
2 & slight discoloration & $3.1-6.0$ \\
3 & apparent discoloration & $6.1-9.0$ \\
4 & severe discoloration & $9.1-12.0$ \\
5 & complete discoloration & $>12.0$ \\
\hline
\end{tabular}

Table 6. Effect of pigment slurry concentration on the level of waterborne wood coating for chemical resistance.

\begin{tabular}{ccccc}
\hline $\begin{array}{c}\text { Concentration of Thermochromic } \\
\text { Pigment Slurry (\%) }\end{array}$ & $\begin{array}{c}\text { NaCl } \\
\text { (level) }\end{array}$ & $\begin{array}{c}\text { Detergent } \\
\text { (level) }\end{array}$ & $\begin{array}{c}\text { Ethanol } \\
\text { (level) }\end{array}$ & $\begin{array}{c}\text { Red Ink } \\
\text { (level) }\end{array}$ \\
\hline 0 & 0 & 0 & 0 & 1 \\
5.0 & 0 & 0 & 0 & 1 \\
10.0 & 1 & 0 & 0 & 0 \\
15.0 & 0 & 0 & 0 & 0 \\
20.0 & 0 & 0 & 0 & 0 \\
25.0 & 0 & 0 & 0 & 0 \\
30.0 & 0 & 0 & 0 & 0 \\
\hline
\end{tabular}

\subsection{Microstructure Analysis}

The above results showed that the waterborne wood coating has good discoloration ability when the concentration of the thermochromic pigment slurry was $15.0 \%$, and the gloss, mechanical properties, and chemical resistance were basically unchanged compared with the original coatings, which can ensure the original performance of the coating. Therefore, the distribution of the thermochromic pigment slurry in the waterborne wood coating was subjected to SEM analysis. As can be seen from Figure 3, the waterborne wood coating was smooth and had almost no particles (Figure 3A). The thermochromic microcapsules are uniform spheres with a diameter of about 5-8 $\mu \mathrm{m}$. The waterborne wood coating with $15.0 \%$ pigment slurry of thermochromic microcapsules had obvious particles and was partially agglomerated, but less than $30.0 \%$ of the thermochromic coating. With the increase of the concentration of the thermochromic pigment slurry, the particles of thermochromic pigment slurry increased, which leads to more agglomeration of pigment particles in the waterborne wood coating. When the concentration was $15.0 \%$, the particle agglomeration in the microstructure of the waterborne wood coating was less, the pigment slurry of thermochromic microcapsule concentration was moderate, and the thermochromic effect was good. 


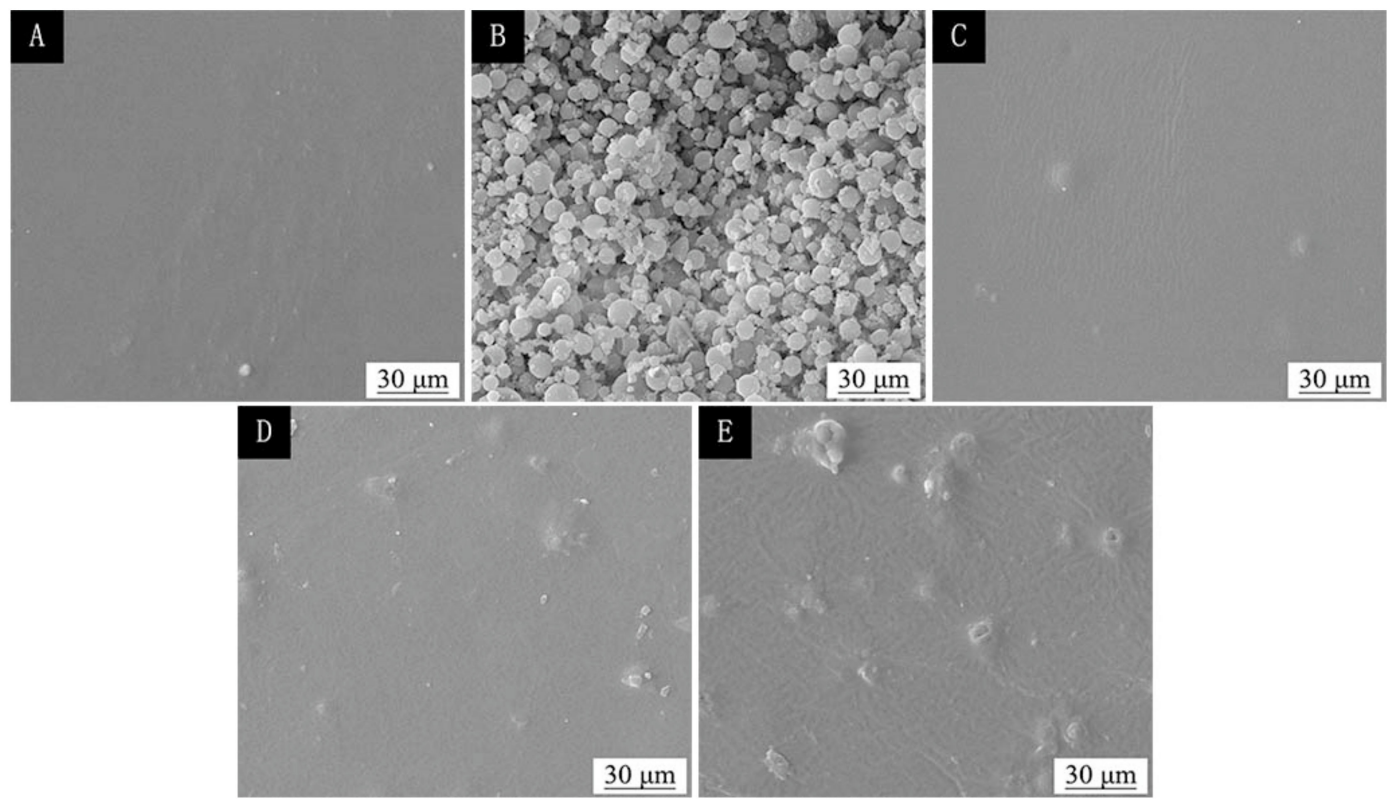

Figure 3. SEM of the waterborne wood coating with different concentrations of thermochromic pigment slurry: (A) waterborne wood coating, (B) thermochromic microcapsules, (C) 5.0\%, (D) 15.0\%, and (E) $30.0 \%$ pigment slurry of thermochromic microcapsules in the waterborne wood coating.

\subsection{Stability of Thermochromic of Coatings}

The waterborne wood coatings with $15.0 \%$ pigment slurry had better color change, gloss, adhesion, impact resistance and chemical resistance. Therefore, the stability [26] of the thermochromic coatings was tested after three months. The chromatic values of the waterborne wood coating after three months at room temperature and three consecutive days in a $30^{\circ} \mathrm{C}$ oven were measured as shown in Table 7, and the color difference calculated according to formula (1) was 1.4-1.7, i.e., there was no obvious color change. This showed that the time at $18{ }^{\circ} \mathrm{C}$ after three months and at $30^{\circ} \mathrm{C}$ for three days had little effect on the chromatic value performance of the waterborne wood coating with the $15.0 \%$ thermochromic pigment slurry concentration and that the thermochromic effect of waterborne wood coating was stable.

The waterborne wood coatings containing a $15.0 \%$ concentration of pigment slurry underwent the ultraviolet weather resistance test for $200 \mathrm{~h}$. The chromatic values and gloss (Table 8) of the waterborne wood coatings were measured. The waterborne wood coatings were analyzed by SEM (Figure 4). The results showed that after ultraviolet-accelerated ageing, the color difference of the waterborne wood coatings was 3.1, which is slightly discoloration (Tables 5 and 8). After the ultraviolet weather resistance test, the gloss of the waterborne wood coatings containing $15.0 \%$ pigment slurry basically did not change. No cracking was observed on SEM, which indicated that the waterborne wood coatings had good stability and ageing resistance during the ultraviolet weather resistance test.

Table 7. Effect of time on chromatic values of thermochromic waterborne wood coating.

\begin{tabular}{ccccccc}
\hline Sample & $\boldsymbol{L}^{*}$ & $\boldsymbol{a}^{*}$ & $\boldsymbol{b}^{*}$ & $\boldsymbol{C}^{*}$ & $\boldsymbol{h}^{*}$ & $\boldsymbol{\Delta} \boldsymbol{E}^{*}$ \\
\hline $18{ }^{\circ} \mathrm{C}$ & $67.7 \pm 0$ & $34.6 \pm 0$ & $26.0 \pm 0$ & $43.3 \pm 0$ & $36.9 \pm 0$ & - \\
Three months at $18{ }^{\circ} \mathrm{C}$ & $67.5 \pm 0$ & $33.7 \pm 0$ & $27.2 \pm 0$ & $44.2 \pm 0$ & $41.2 \pm 0$ & $1.5 \pm 0$ \\
$30^{\circ} \mathrm{C}$ & $74.4 \pm 0$ & $22.9 \pm 0$ & $26.6 \pm 0$ & $35.1 \pm 0$ & $49.2 \pm 0$ & - \\
$30^{\circ} \mathrm{C}$ heating $24 \mathrm{~h}$ & $73.6 \pm 0$ & $23.9 \pm 0$ & $25.5 \pm 0$ & $36.0 \pm 0$ & $48.5 \pm 0$ & $1.7 \pm 0$ \\
$30^{\circ} \mathrm{C}$ heating $48 \mathrm{~h}$ & $73.7 \pm 0$ & $23.8 \pm 0$ & $25.8 \pm 0$ & $34.2 \pm 0$ & $48.6 \pm 0$ & $1.4 \pm 0$ \\
$30^{\circ} \mathrm{C}$ heating $72 \mathrm{~h}$ & $73.9 \pm 0$ & $22.2 \pm 0$ & $27.8 \pm 0$ & $36.4 \pm 0$ & $50.6 \pm 0$ & $1.5 \pm 0$ \\
\hline
\end{tabular}


Table 8. Gloss and chromatic values of waterborne wood coating before and after ageing.

\begin{tabular}{cccccccc}
\hline Sample & $\boldsymbol{L}^{*}$ & $\boldsymbol{a}^{*}$ & $\boldsymbol{b}^{*}$ & $\boldsymbol{C}^{*}$ & $\boldsymbol{h}^{*}$ & $\boldsymbol{\Delta} \boldsymbol{E}^{*}$ & Gloss (\%) \\
\hline Before ageing & $72.2 \pm 0$ & $14.1 \pm 0$ & $36.7 \pm 0$ & $39.3 \pm 0$ & $69.8 \pm 0$ & - & $37.2 \pm 0$ \\
After ageing & $71.8 \pm 0$ & $14.7 \pm 0$ & $39.7 \pm 0$ & $42.3 \pm 0$ & $69.5 \pm 0$ & $3.1 \pm 0$ & $36.8 \pm 0$ \\
\hline
\end{tabular}
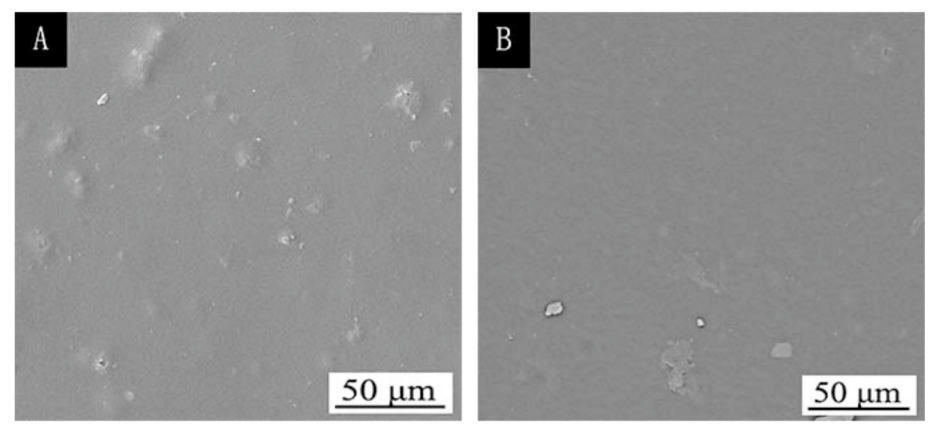

Figure 4. SEM of waterborne wood coatings with 15.0\% pigment slurry: (A) before and (B) after ageing.

\section{Conclusions}

A variable temperature test showed that the waterborne wood coating with $15.0 \%$ thermochromic pigment slurry had better discoloration ability near $30^{\circ} \mathrm{C}$, and the original performance of the coating was maintained. The gloss of the waterborne wood coating decreased with the increase in the concentration of thermochromic pigment slurry. The concentration of the thermochromic pigment slurry had no effect on the adhesion of the waterborne wood coating. When the concentration of the pigment slurry of thermochromic microcapsules was more than $20.0 \%$, the impact resistance of the waterborne wood coating gradually increased with the increase of the thermochromic pigment slurry concentration, but the difference was not significant. The concentration of thermochromic pigment slurry had no effect on the chemical resistance level of the waterborne wood coating. After the temperature dropped to about $18{ }^{\circ} \mathrm{C}$, the waterborne coating returned to its original color, and the color could be changed repeatedly. Based on the above results, the comprehensive performance of the waterborne wood coating on Chinese fir surface is better when the concentration is $15.0 \%$, and waterborne wood coatings have good stability and ageing resistance. This study laid a foundation for intelligent thermochromic coatings on a wood surface.

Author Contributions: Conceptualization, Methodology, Validation, Resources, Data Curation, Writing-Original Draft Preparation, and Supervision, X.Y.; Formal Analysis, X.Q. and Y.C.; Investigation and Writing-Review and Editing, Y.C.

Funding: This project was partly supported by the Natural Science Foundation of Jiangsu Province (BK20150887) and Youth Science and Technology Innovation Fund of Nanjing Forestry University (CX2016018).

Conflicts of Interest: The authors declare no conflict of interest.

\section{References}

1. Tozum, M.S.; Aksoy, S.A.; Alkan, C. Microencapsulation of three-component thermochromic system for reversible color change and thermal energy storage. Fiber. Polym. 2018, 19, 660-669. [CrossRef]

2. Eranki, A.; Mikhail, A.S.; Negussie, A.H.; Katti, P.S.; Wood, B.J.; Partanen, A. Tissue-mimicking thermochromic phantom for characterization of HIFU devices and applications. Int. J. Hyperther. 2019, 36, 518-529. [CrossRef] [PubMed]

3. Basnec, K.; Perse, L.S.; Sumiga, B.; Huskic, M.; Meden, A.; Hladnik, A.; Podgornik, B.B.; Gunde, M.K. Relation between colour- and phase changes of a leuco dye-based thermochromic composite. Sci. Rep. 2018, 8, 5511. [CrossRef] 
4. Youn, J.W.; Lee, S.J.; Kim, K.S.; Kim, D.U. Adhesion characteristics of $\mathrm{VO}_{2}$ ink film sintered by intense pulsed light for smart window. Appl. Surf. Sci. 2018, 441, 508-514. [CrossRef]

5. Jakovljevic, M.; Lozo, B.; Gunde, M.K. Spectroscopic evaluation of the colour play effect of thermochromic liquid crystal printing inks. Color. Technol. 2017, 133, 81-87. [CrossRef]

6. Wang, G.L.; Xu, W.; Xu, F.; Shen, W.F.; Song, W.J. AgNW/Chinese Xuan paper film heaters for electro-thermochromic paper display. Mater. Res. Express 2017, 4, 116405. [CrossRef]

7. Khatami, A.; Prova, S.S.; Bagga, A.K.; Ting, M.Y.C.; Brar, G.; Ifa, D.R. Detection and imaging of thermochromic ink compounds in erasable pens using desorption electrospray ionization mass spectrometry. Rapid Commun. Mass Spectrom. 2017, 31, 983-990. [CrossRef] [PubMed]

8. De Bastiani, M.; Saidaminov, M.I.; Dursun, I.; Sinatra, L.; Peng, W.; Buttner, U.; Mohammed, O.F.; Bakr, O.M. Thermochromic perovskite inks for reversible smart window applications. Chem. Mater. 2017, 29, 3367-3370. [CrossRef]

9. Vukoje, M.; Miljanic, S.; Hrenovic, J.; Rozic, M. Thermochromic ink-paper interactions and their role in biodegradation of UV curable prints. Cellulose 2018, 25, 6121-6138. [CrossRef]

10. Kavcic, U.; Mraovic, M.; Bracko, S.; Muck, D. Printed thermochromic displays. Color. Technol. 2019, 135, 60-66. [CrossRef]

11. Panak, O.; Drzkova, M.; Kailova, N.; Syrovy, T. Colorimetric analysis of thermochromic samples in different forms employing a digital camera. Measurement 2018, 127, 554-564. [CrossRef]

12. Kim, M.J.; Angupillai, S.; Min, K.; Ramalingam, M.; Son, Y.A. Tuning of the topochemical polymerization of diacetylenes based on an odd/even effect of the peripheral alkyl chain: Thermochromic reversibility in a thin film and a single-component ink for a fountain pen. ACS Appl. Mater. Interfaces 2018, 10, 24767-24775. [CrossRef] [PubMed]

13. Zhu, X.D.; Liu, Y.; Li, Z.; Wang, W.C. Thermochromic microcapsules with highly transparent shells obtained through in-situ polymerization of urea formaldehyde around thermochromic cores for smart wood coatings. Sci. Rep. 2018, 8, 4015. [CrossRef] [PubMed]

14. Zhu, X.D.; Liu, Y.; Dong, N.W.; Li, Z. Fabrication and characterization of reversible thermochromic wood veneers. Sci. Rep. 2017, 7, 16933. [CrossRef] [PubMed]

15. Yan, X.X.; Wang, L.; Qian, X.Y. Effect of high-temperature calcined wheat straw powder after lignin removal on properties of waterborne wood coatings. Coatings 2019, 9, 444. [CrossRef]

16. Yan, X.X.; Wang, L.; Qian, X.Y. Effect of urea-formaldehyde-coated epoxy microcapsule modification on gloss, toughness and chromatic distortion of acrylic copolymers waterborne coating. Coatings 2019, 9, 239. [CrossRef]

17. Gaikwad, M.S.; Kusumkar, V.V.; Yemul, O.S.; Hundiwale, D.G.; Mahulikar, P.P. Eco-friendly waterborne coating from bio-based polyester amide resin. Polym. Bull. 2019, 76, 2743-2763. [CrossRef]

18. Chen, R.D.; Huang, C.F.; Hsu, S.H. Composites of waterborne polyurethane and cellulose nanofibers for 3D printing and bioapplications. Carbohydr. Polym. 2019, 212, 75-88. [CrossRef]

19. Li, J.; Luo, D.W.; Ma, G.F.; Jia, L.C.; Xu, J.L.; Huang, H.H.; Tong, Z.K.; Lu, Y.Q. Response of Chinese fir seedlings to low phosphorus stress and analysis of gene expression differences. J. For. Res. 2019, 30, 183-192. [CrossRef]

20. Malm, V.; Straat, M.; Walkenstrom, P. Effects of surface structure and substrate color on color differences in textile coatings containing effect pigments. Text. Res. J. 2014, 84, 125-139. [CrossRef]

21. SAC. GB/T 1732-93 Determination of Impact Resistance of Film; Standardization Administration of the People's Republic of China: Beijing, China, 1993.

22. SAC. GB/T 1720-89 Determination of Adhesion of Film; Standardization Administration of the People's Republic of China: Beijing, China, 1979.

23. SAC. GB/T 1733-93 Determination of Resistance to Water of Films; Standardization Administration of the People's Republic of China: Beijing, China, 1993.

24. Li, B.Z.; Du, C.Q.; Tan, M.L.; Liu, H.; Essah, E.; Yao, R.M. A modified method of evaluating the impact of air humidity on human acceptable air temperatures in hot-humid environments. Energy Build. 2018, 158, 393-405. [CrossRef] 
25. SAC. GB/T 11186.3-1989 Method of Measurement of Coating Color. Part III: Calculation of Chromatic Aberration; Standardization Administration of the People's Republic of China: Beijing, China, 1990.

26. Friskovec, M.; Kulcar, R.; Gunde, M.K. Light fastness and high-temperature stability of thermochromic printing inks. Color. Technol. 2013, 129, 214-222. [CrossRef]

(C) 2019 by the authors. Licensee MDPI, Basel, Switzerland. This article is an open access article distributed under the terms and conditions of the Creative Commons Attribution (CC BY) license (http://creativecommons.org/licenses/by/4.0/). 